\title{
Co-evolutionary and multi-level dynamics in transitions: The transformation of aviation systems and the shift from propeller to turbojet (1930-1970)
}

\author{
F.W. Geels* \\ Department of Technology Management, Eindhoven University of Technology, IPO 2.10, P.O. Box 513, 5600 MB Eindhoven, The Netherlands
}

\begin{abstract}
This article deals with system innovation in Freeman and Perez's innovation typology (incremental, radical, system, techno-economic paradigm). This article conceptualises these changes as transitions from one socio-technical system to another. These transitions are coevolution processes that are not only about technological discontinuities, but also about markets, user practices, regulation, culture, infrastructure and science. In a critical discussion of co-evolution literatures, the article distinguishes three levels of co-evolutionary processes. To understand transitions, these insights are combined in a multi-level perspective, consisting of niche, regime and landscape levels. Transitions come about when co-evolutionary dynamics at these three levels link up and reinforce each other. The perspective is illustrated with a historical case study: the transition from aviation systems based on propeller-aircraft to aviation systems based on turbojet aircraft (1930-1970). The case study provides not just an evolutionary economic analysis of technological change, but also deals with the long-run evolution of technology and the socio-economic system.
\end{abstract}

(C) 2005 Elsevier Ltd. All rights reserved.

Keywords: Co-evolution; Transition; Multi-level perspective; Turbojet; Aviation

\section{Introduction}

Co-evolution is emerging as an important concept in a range of disciplines, e.g. evolutionary economics, innovation studies, industrial economics, and long-wave theories. It has always been an important theme in the sociology of technology, with its emphasis on seamless webs, emerging linkages between heterogeneous elements and co-construction. Different aspects of co-evolution have described, e.g.:

- Co-evolution between technology and users (Coombs et al., 2001; Lundvall, 1988; Clark, 1985; Leonard-Barton, 1988; Oudshoorn and Pinch, 2003).

- Co-evolution between technology, industry structure and policy institutions (Nelson, 1994a, b; Van de Ven and Garud, 1994; Rosenkopf and Tushman, 1994; Leydesdorff and Etzkowitz, 1998; Leydesdorff, 2000).

\footnotetext{
*Tel. + 3104024754514 ; fax: + 310402444602 .

E-mail address: F.W.Geels@tm.tue.nl.
}

- Co-evolution of science, technology and the market (Callon et al., 1992; Stankiewicz, 1992).

- Co-evolution of science and technology (Kline and Rosenberg, 1986; Layton, 1971, 1976).

- Co-evolution of technology and culture (Du Gay et al., 1997; Van Dijck, 1998).

This summing up shows that co-evolution has been studied with regard to two or three aspects. But a broader study of co-evolution seems to be lacking. Such a broader study of co-evolution is needed to understand innovations at higher aggregation levels and longer time-scales, such as the two highest levels of Freeman and Perez's innovation typology. Freeman and Perez (1988) distinguish four kinds of innovations. Incremental innovations occur more or less continuously in any industry to improve price and performance. Radical innovations are discontinuous events, which are unevenly distributed over sectors and over time. Whenever they occur they are important as the potential springboard for the growth of new markets, and for 
the surges of new investment associated with booms. They often involve a combined product, process and organisational innovation. Changes of technology system are far-reaching changes in technology, affecting several branches of the economy, as well as giving rise to entirely new sectors. They are based on a combination of radical and incremental innovations, together with organisational and managerial innovations affecting more than one or a few firms. Changes in the 'techno-economic paradigm' (TEP) are far-reaching and affect the entire economy. The changes involved go beyond engineering trajectories for specific product or process technologies and affect the input cost structure and the conditions of production and distribution throughout the system.

Changes in TEP are studied in long-wave theories, and radical innovations are the topic of many literatures in business studies and innovation studies. But transitions in technology systems are under-addressed. Existing literatures that carry the term 'systems' have conceptualised many interesting topics, but did little to address changes from one system to another. Sectoral systems of innovation (Breschi and Malerba, 1997; Malerba, 2002) are defined as "a system (group) of firms active in developing and making a sector's products and in generating and utilising a sector's technologies" (Breschi and Malerba, 1997, p. 131). Likewise, the technological systems approach (Carlsson and Stankiewicz, 1991, Carlsson, 1997) looks at "networks of agents interacting in a specific technology area under a particular institutional infrastructure to generate, diffuse and utilise technology" (Carlsson and Stankiewicz, 1991, p. 111). Both approaches widened the attention in innovation studies from firms to networks of actors involved in technological innovation, focusing attention on interaction, knowledge flows, network dynamics and co-evolution. But the approaches say more about the functioning of systems than about their change. The Large Technical Systems (LTS) approach pays more explicit attention to both social and material aspects of technological systems (Hughes, 1983, 1987; Mayntz and Hughes, 1988). But the LTS approach is more about the emergence of infrastructural systems (e.g. electricity networks, railroad networks, telephone systems) than about the change from one system to another. The Complex Products and Systems (CoPS) approach (Miller et al., 1995; Hobday, 1998; Hobday et al., 2000) has a particular object of analysis, namely high cost, technology-intensive, customised, capital goods, such as flight simulation systems, bridges, chemical plants, robotics equipment, and submarines. The products are systemic because they work through the interplay of many interacting components. But the CoPS approach does not look at technology systems at the sectoral level nor at transitions from one system to another. Such transitions and system innovations are the topic of this article.

To conceptualise Freeman and Perez's 'technology systems', the article builds on the sociology of technology. Artefacts by themselves have no power, they do nothing. Only in association with human agency and social structures and organisations do artefacts fulfil functions.
In real-life situations (e.g. organisations, houses, cities) we never encounter artefacts 'per se', but artefacts-in-context. For the analysis of functioning artefacts, it is the combination of 'the social' and 'the technical' that is the appropriate unit of analysis (Fleck, 1993, 2000). From sociology of technology two basic notions of technology are important: (a) technology is heterogeneous, not just a material contraption; engineers know this, their work is 'heterogeneous engineering' (Law, 1987), (b) the functioning of technologies involves linkages between heterogeneous elements. Hughes (1987) coined the metaphor of a 'seamless web' to indicate how physical artefacts, organisations (e.g. manufacturing firms, investment banks, research and development laboratories), natural resources, scientific elements (e.g. books, articles), legislative artefacts (e.g. laws) are combined in order to achieve functionalities. At the sectoral level, I conceptualise the cluster of heterogeneous elements as socio-technical systems (Geels, 2004). ${ }^{1}$ Socio-technical systems are heterogeneous configurations with elements such as technology, regulation, user practices, markets, cultural meaning, infrastructure, maintenance networks, science and supply networks (see Fig. 1 for an example of the aviation system).

The research question in this article is: how do coevolutionary dynamics play a role in transitions from one socio-technical system to another? Section 2 provides a critical discussion of different co-evolution approaches, positioning them at different analytical levels. Section 3 integrates the approaches in a multi-level perspective (MLP) on transitions. The perspective argues that transitions come about when co-evolutionary dynamics at different levels align and link up. In Section 4, this perspective is empirically illustrated with a historical case study: the transformation in aviation systems associated with the shift from piston engine aircraft to jetliners (1930-1970). The article ends with conclusions in Section 5.

\section{Co-evolution at different levels}

This section shows that different co-evolutionary approaches address different levels and units of analysis. The main distinction is between a level of emerging innovations, a level of existing configurations or systems, and a macro-level of society as a whole. This is not the same as the traditional economic micro-meso-macro distinction of levels, where the micro-level is formed by concrete agents, the meso-level by networks between agents and the macro-level by outcomes such as economic growth. The distinction in this section is based on different levels of

\footnotetext{
${ }^{1}$ The concept of socio-technical systems has been used at the firm level in organisation and management theory. The interdependence of social and technical systems of organisation was one of the core insights of the socio-technical systems tradition associated with the Tavistock School (Trist and Murray, 1990, 1993; Emery, 1993; Griffith and Dougherty, 2001). This tradition highlights that human beings and machines are joined together in industrial workplace settings. The focus in this article, however, is not on the firm level but at the sectoral level.
} 


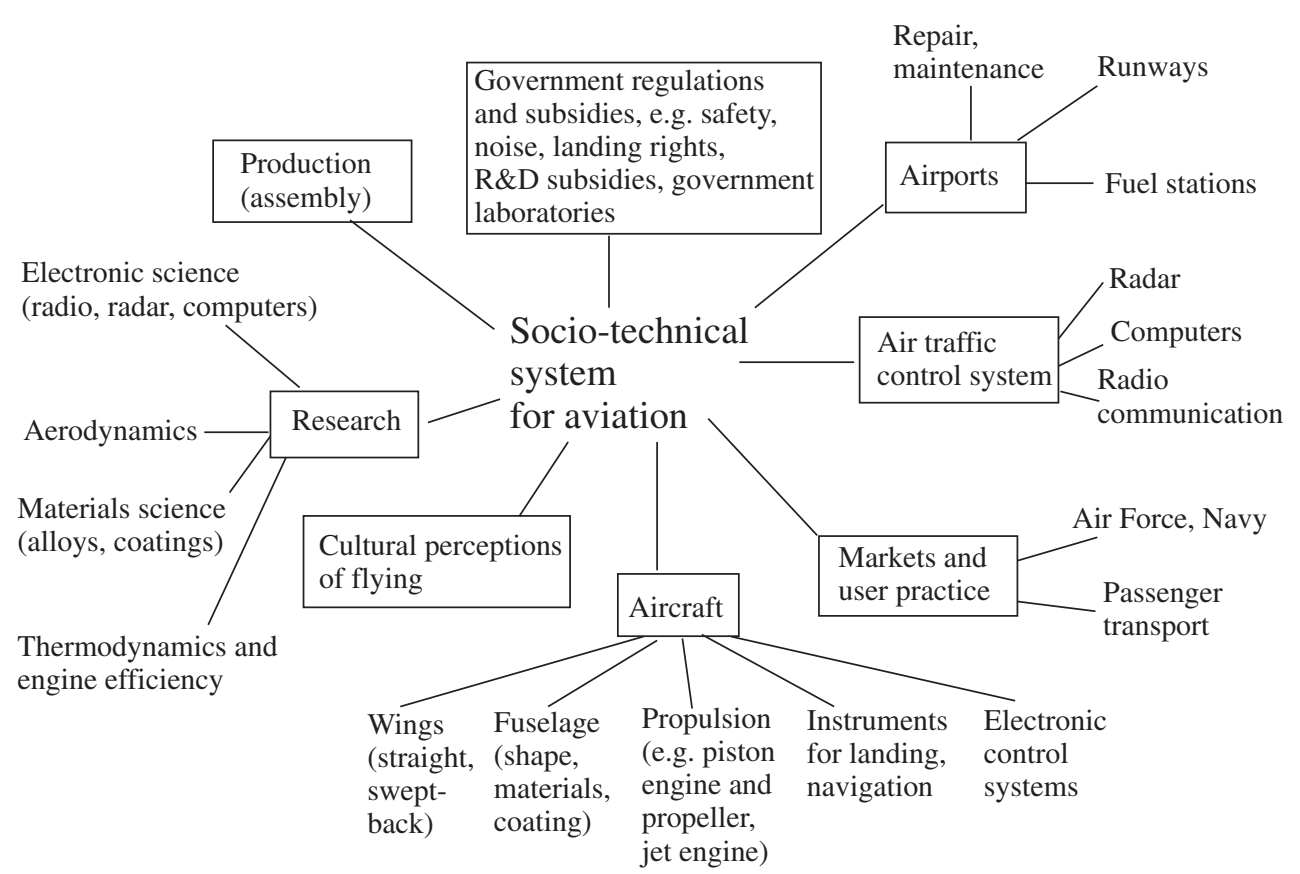

Fig. 1. Socio-technical system for aviation.

innovation, with different degrees of hardness and structural stability. Emerging innovations are relatively fluid with limited stability. Existing systems are relatively hard and stable, but still depend on human (re)production. The macro-level of society is hardened and forms the backdrop of human action.

\subsection{Co-construction at the level of emerging innovations}

At the level of new, emerging innovations, the main dynamic is co-construction, or alignment of heterogeneous elements into a working configuration. The LTS approach (e.g. Hughes, 1983, 1987; Mayntz and Hughes, 1988; Summerton, 1994) describes how new technologies and user contexts are shaped simultaneously as they are woven into 'seamless webs'. LTS-scholars highlight the work of system builders, who mould technologies, economics, regulations and user preferences into a configuration that works. The elements are initially vague, diffuse, and consist in a variety of shapes. As the elements become more aligned, boundaries are shaped, and roles and responsibilities become demarcated. Stabilisation leads to the creation of boundaries between social, technical, political, economic elements. Shaping technology and building society are seen as two sides of the same coin (Bijker and Law, 1992).

Co-construction is also emphasised in Actor-Network Theory, ANT (e.g. Latour, 1987, 1991; Callon, 1991; Law and Callon, 1992; Law and Hassard, 1999), using a more abstract approach to describe how elements are shaped and linked together (e.g. translation, enrolment, alignment). Actor-network theorists argue that technology gradually becomes more 'real' as more elements are linked together, while it develops from an invention to a material prototype to a commercial artefact sold on the market.

Innovation studies and sociology of technology highlight the active role of users in the co-construction of technology, markets and users (Coombs et al., 2001; Oudshoorn and Pinch, 2003). For radically new technologies, stable markets and 'rules of the game' (e.g. property rights, quality norms, trust) do not yet exist. In a case study of a particular biotechnology-innovation, Green (1992) showed that firms tried to create a new market through 'constituency building', involving regulatory agencies, standard-setting bodies, users and external sources of finance. The innovation failed because the elements were not successfully aligned. User-producer interactions are crucial to articulate and align the different elements of new innovations (Lundvall, 1988). Users play active roles in the articulation of user preferences, exploration of new functionalities, feedback of user experiences to designers, and learning by using (Rosenberg, 1982). Because the coconstruction process of new innovations is non-linear and uncertain, firms engage in market experimentation, probing market segments with prototypes, learning from experience (Lynn et al., 1996).

These companies developed their products by probing initial markets with early versions of the products, learning from the probes, and probing again. In effect, they ran series of market experiments, introducing prototypes into a variety of market segments. (...) The approach at work in these cases might best be described as probing and learning. (...) Probing with immature versions of the product only makes sense if it serves as a vehicle for learning about the technology, and whether and how it can be scaled up, about the market, (...) 
and about government regulations and the need for regulatory approvals. (...). Development of a discontinuous innovation becomes a process of successive approximation, probing and learning again and again (Lynn et al., 1996, pp. 15-19; italics added).

Although the final outcome is unknown, the probing and learning process is not blind. Instead, it is guided in each step by visions, expectations and ideas about possible uses. These visions and expectations are changed on the basis of the outcomes of learning processes.

\subsection{Co-evolution at the level of existing configurations}

There are also approaches that focus on co-evolution at the level of established socio-technical configurations. These approaches look at interdependent, but relatively autonomous sub-systems that have internal dynamics of their own. Boundaries between the sub-systems are the outcome of the stabilisation of previous co-construction processes. The dynamics of sub-systems influence each other and co-evolve. This interrelatedness is represented in terms such as triple helix, techno-economic networks (Callon, 1991), and techno-institutional complex (Unruh, 2000). Co-evolution is conceptualised as relatively autonomous 'streams' that influence each other.

In the triple helix perspective, the focus is on the ongoing co-evolution between university, government and industry. (Leydesdorff and Etzkowitz, 1998; Etzkowitz and Leydesdorff, 2000). The ongoing co-evolution is represented with three helices, interacting through communication networks and linkages. During the co-evolution process, tensions and a-synchronicities may emerge. 'Uncertainties in the relations between the helices open windows of potential innovation (and conflict) in (sub)systems that otherwise have to be reproduced' (Leydesdorff, 2000, p. 244). These tensions in existing configurations may create windows of opportunity for the emergence and diffusion of radical innovations.

Co-evolution in existing configurations has also been studied in actor-network theory. As networks of heterogeneous linkages grow longer, they may develop into techno-economic networks with differentiated 'poles', representing a distribution of labour (Callon, 1991; Callon et al., 1992). A techno-economic network is a 'coordinated set of heterogeneous actors, e.g. public laboratories, technical research centres, industrial firms, financial organisations, users, and public authorities, which participate collectively in the development and diffusion of innovations' (Callon et al., 1992, p. 220). In the original approach there are three main poles: science, technology and market. Interaction and coordination between these poles is provided by the circulation of so-called intermediaries, e.g. written documents (scientific articles, reports, patents, etc.), people and their skills, money (e.g. contracts, loans, purchase), and technical objects (e.g. prototypes, machines, products). The dynamics of scientific change, technological invention and the expression of demand are processes that are mixed up in each other. The network can be stable (cold, closed) or unstable (warm, fluid). In stable situations, the direction of innovation can be explained inductively, as a continuation of ongoing developments. Elements are strongly linked in convergent network. In unstable situations there is less predictability. Linkages between elements weaken, creating windows of opportunity for the introduction of new elements. The situation of the network thus determines whether a radical novelty is adopted or not. In cold situations, the stability of the network provides a barrier for the novelty to break through (Callon et al., 1992). If a network is 'heating up' and becomes unstable, windows of opportunity may emerge to which radical technologies can link up.

\subsection{Co-evolution at the macro-level}

At the macro-level of entire societies, co-evolution is conceptualised in long-wave theories. To explain approximately 50-year (Kondriatiev) cycles in prices and economic growth, long wave theorists argued that pervasive radical innovations are important (e.g. Freeman and Perez, 1988; Tylecote, 1993; Freeman and Louçă, 2001). To understand macro-changes in the economy, Freeman and Perez (1988) coined the concept of 'techno economic paradigm' (TEP) to indicate periods in which pervasive technologies, methods of production and economic structures reinforce each other. They distinguish four historical successions in TEP: (a) water power, sail shipping, mechanisation in textiles (1770-1830), (b) steam power and iron, applied in railways and steamships (1830-1880), (c) electricity and heavy engineering with steel (1880-1930), and (d) automobiles, aircraft, oil and petrochemicals, synthetic materials (1930-1980). Freeman and Perez claim that we are currently in the middle of the fifth cycle, related to information technology and biotechnology. In each TEP, a particular set of inputs is the 'key factor'. For the five TEP's these key factors are: (a) cotton, pig iron, (b) coal, transport, (c) steel, (d) energy (oil), (e) information (chips and micro-electronics). Transitions from one TEP to another are complex and co-evolutionary processes. A new technology emerges in a world that is still dominated by the old paradigm, and demonstrates its advantages first in one or a few sectors. The emergence of radical innovations is explained as a reaction to problems in the existing TEP, in particular perceived limits to growth, diminishing returns in productivity and a weakening of the key factor. Conversely, as long as the existing TEP is stable, new technologies have no chance of breaking through. New technologies may also be held back because they do not fit the existing institutional and social framework. 'Initially there will be a degree of mismatch between the techno-economic subsystem and the old socioinstitutional framework' (Freeman and Perez, 1988, p. 59). But as the key factor of the old TEP runs into problems, the new technology acquires a dynamic of its own. To 
overcome the initial mis-match, wider changes take place as the technology diffuses, e.g. in organisational forms in the firm and at plant level, new skill profile in labour force, new product mix, wave of infrastructural investment, tendency for new innovator-entrepreneur-type small firms to enter expanding branches of economy, new pattern of consumption of goods and services; and new types of distribution and consumer behaviour (Freeman and Perez, 1988, p. 59). Diffusion thus involves changes on many aspects.

This version of long-wave theory has been criticised for its deterministic overtones. Innovations simply emerge in response to 'key factors', limits and bottlenecks in the existing TEP. To prevent determinism, macro-theories should also pay attention to micro-processes, e.g. the perceptions and activities of actors involved in developing new technologies. Macro-aspects should be combined with micro-processes in a coherent perspective. This means we need a multi-level perspective. The criticism of technological determinism also stems from the fact that the suggested causality is that techno-economic forces do the initial acting and the socio-institutional framework does the subsequent reacting. In response to this criticism, Freeman and Louçă (2001) made further refinements to long-wave theory, distinguishing five equally important 'sub-systems' in society: science, technology, economy, politics and culture. These subsystems have their own distinctive features, their own 'selection' environment, and relative autonomous dynamics. These sub-systems interact with each other, because activities of social groups are coordinated and aligned to each other. Freeman and Louçă propose that long-waves dynamics can be understood as co-evolutionary processes with periods of alignment and periods of de-alignment between the five sub-systems. The sub-systems have specific cycles and generate irregular fluctuations and variations (e.g. political cycles, business cycles, technological trajectories, cultural movements, lifecycle of industries). These fluctuations are usually dampened by the linkages with other sub-systems. At times, however, the fluctuations result in major mal-adjustments and lack of synchronicities. These tensions between subsystems are the underlying cause of periods of economic crises. Tensions may be overcome through innovations in the sub-systems and gradual re-alignment. Renewed positive congruence between the sub-systems may provide fertile soil for renewed economic growth. Thus, it is essential to study both the relatively independent development of each stream of history and their interdependencies, their loss of integration, and their reintegration' (p. 127). The intuition to understand major changes as de-alignment and re-alignment processes between different elements is interesting and will be further elaborated in Section 3.

Co-evolution at the level of society can also be found in the work of some general historians that have written synthesising works, trying to weave together different strands of historical processes, e.g. Johan Huizinga, Jan Romein, Manuel Castells and Fernand Braudel. The French historian Braudel $(1976,1985 \mathrm{a}-\mathrm{c})$ is particularly interesting, because he developed a conceptual framework that distinguishes different levels of historical time. Braudel has written about the changes in Europe from Medieval to early modern society (15-18th century). He analysed these changes as co-evolution between processes such as demographics, food provision, environmental conditions (such as droughts, floods, rainfall patterns, temperature), and technological innovations in energy sources, metallurgy, transportation, gunpowder, printing, and sea navigation. Culture is also important, for instance in the form of fashions, table manners, and the use of luxuries such as, salt, meat and spices. Wars, treaties, kings and popes only feature incidentally in his work. Their actions are events against the backdrop of wider social, cultural, economic, technological and environmental conditions. At the heart of Braudel's synthesis is a three-level hierarchy, which distinguishes different speeds of historical developments (see Fig. 2). The macro-level is formed by deep structures with rhythms of 50-100 years, the 'longue durée' (Braudel, 1958). This level refers to aspects such as geographical landscapes, which influence communication and trading patterns (e.g. the shape the Mediterranean Sea, mountain ranges, rivers), demographics and environmental conditions (soil, climate, rainfall). These structures cannot be changed at will by human actors and provide the backdrop for action. The meso-level refers to cyclic processes in domains such as agriculture, transport, economy, military logistics, politics, cultural values, communication and trading patterns. The time frame is that of decades. To understand dynamics at this level, Braudel looks at interactions between social groups such as large landowners, nobility, bourgeoisie, urban craftsmen, peasants, traders, military leaders, city governments. The micro-level is that of political, diplomatic and military events with a time-length of months and years. This is the stuff of traditional historical accounts that look at triumphs and failures of 'big men' (kings, military leaders). For Braudel this is a superficial level that cannot explain the whole of history.

Braudel's work has a structuralist bias, tending towards a top-down explanation, where historical developments are understood from the structures in which they are

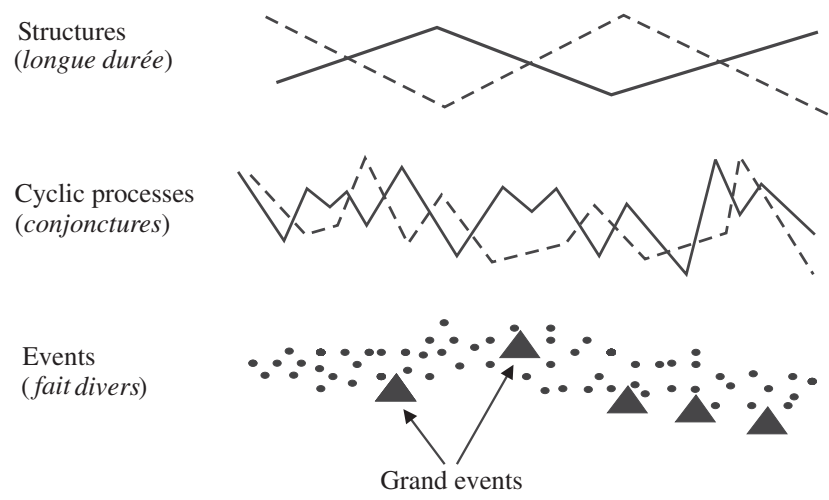

Fig. 2. Different historical time-developments (Bertels, 1973, p. 123). 
embedded. This bias can be overcome, when the structuralist perspective is complemented with a bottom-up perspective. This will be done in the next section.

\section{A co-evolutionary multi-level perspective on transitions}

To understand transitions the multi-level perspective (MLP) provides a useful framework (Schot et al., 1994; Rip and Kemp, 1998; Geels, 2002, 2004, 2005). The MLP distinguishes three analytical and heuristic levels (niche, regime and landscape) that capture the three levels distinguished in Section 2, and conceptualise them in evolutionary terms.

Technological niches form the level where radical innovations emerge through co-construction processes. Niches act as 'incubation rooms' for radical novelties, shielding them from mainstream market selection (Schot, 1998). Niches may have the form of small market niches, where selection criteria are different from the existing regime. Or they may have the form of technological niches, where resources are provided by public subsidies or private strategic investments. These technological niches function as 'proto-markets' when market demand is not yet present. Technological and small market niches have two dimensions emphasised in different disciplines: ecological and socio-cognitive. The first dimension highlights the importance of a sheltered place with particular resources (either from consumers or subsidies), something that is also mentioned by some evolutionary economists (e.g. Saviotti, 1996; Levinthal, 1998; Tisdell and Seidl, 2004). They argue that small market niches provide a trickle of resources that enable a new technology to survive and develop in relative isolation. This aspect of a technological niche is comparable to the notion of biological niche, i.e. a particular place in ecological food webs that provide material and energy flows. The concept of niches can also be found in organisational ecology (e.g. Carroll, 1988; Hannan and Freeman, 1989; Carroll and Harrison, 1994). But the focus in this literature is on the effects of the width of market niches on competition in populations of firms. The concept of technological niche is more about a 'technological ecology' than an organisational ecology. The second, socio-cognitive dimension of technological niches is an addition from sociology of technology, emphasising the importance of social networks and the coordination of activities by shared rules and perceptions. In niches, the social networks around new technologies are usually small, and the cognitive rules unstable. There is little stability and much uncertainty, and actors work in different directions, exploring different trajectories. From this background, the literature on strategic niche management distinguishes three important niche-internal processes (Schot et al., 1994; Kemp et al. 1998, 2001; Hoogma et al., 2002). The first process is learning. To create a working configuration, learning and co-construction processes are important on several dimensions, e.g. technology, user preferences, regulation, symbolic meaning, infrastructure, and produc- tion systems. The second process is the building of social networks and constituencies that support the new innovation and invest in its further development. The third process is the articulation of visions and expectations to provide orientation towards the future and give direction to learning processes. These three niche-internal processes thus conceptualise the role of actors in co-construction processes.

The meso-level is formed by socio-technical regimes. This concept builds on Nelson and Winter's (1982) notion of technological regimes, that refers to cognitive routines (e.g. search heuristics, exemplars) shared by engineers and designers in a technical community. Technological regimes create stability, because engineers in different firms search and work in similar directions. This results in technological trajectories at the sectoral level, i.e. incremental changes to refine existing technologies in particular directions. But socio-technical systems at the sectoral level are not only related to activities of engineers, but also to activities of other social groups. Fig. 3 gives an impression of the social groups involved in aviation and their interrelationships. To encompass these multiple social groups, the concept of socio-technical regime is used.

The activities of these social groups (re)produce and maintain the elements and linkages in socio-technical systems. The groups are interdependent and interacting with each other, leading to coordination and alignment. Socio-technical regimes account for dynamic stability of socio-technical systems, meaning that innovation still occurs but is of an incremental nature, leading to trajectories and path dependencies.

The macro-level is formed by the socio-technical landscape, which refers to aspects of the exogenous environment. The content of the socio-technical landscape is heterogeneous and may include aspects such as economic growth, broad political coalitions, cultural and normative values, environmental problems, resource scarcities. But the socio-technical landscape also includes the large-scale material context of society, e.g. the material and spatial arrangements of cities, factories, highways, and electricity infrastructures (Rip and Kemp, 1998). Landscapes are beyond the direct influence of actors, and cannot be changed at will. In that sense the landscape is similar to Braudel's 'longue durée'. Changes at the landscape level usually take place slowly, in the order of decades, but can sometimes occur rapidly (e.g. war, rapid increase in oil price).

The key point of the MLP is that transitions come about through the interplay between dynamics at multiple levels. Several phases can be distinguished (Rotmans et al., 2001; Geels, 2005). In the first phase, novelties emerge in niches in the context of existing regime and landscape developments. There is not yet a dominant design, and various technical forms may be competing with each other. Actors improvise, engage in experiments to work out the best design and try to align heterogeneous elements in coconstruction processes. Actors support the niche, hoping 


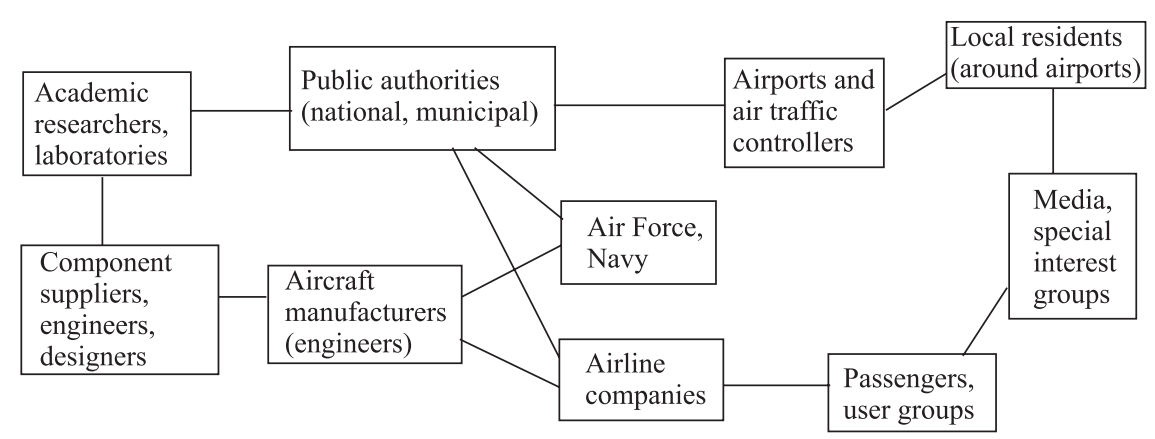

Fig. 3. Social groups in aviation.

that novelties will eventually be used in the regime or even replace it. This is not easy, because the existing regime is entrenched in many ways (e.g. institutionally, organisationally, economically, culturally). Radical novelties often have a mis-match with the existing regime and do not easily break through.

In the second phase, the novelty is used in small market niches, which provide resources for technical specialisation. Gradually, a dedicated community of engineers and producers emerges, directing their activities to further improvement of the new technology. As this community articulates new rules, the emerging technology develops a trajectory of its own. As users interact with the new technology and incorporate them into their user practices, they build up experience with it, and gradually explore new functionalities.

The third phase is characterised by a breakthrough of the new technology, wide diffusion and competition with the established regime. There are two complementary drivers. On the one hand, there are internal drivers in the niche, e.g. price/performance improvements, increasing returns to adoption, virtuous cycles of niche-internal processes, and actors with vested interests that push for diffusion of the technology. On the other hand, breakthrough of technologies from the niche-level depends on external circumstances at the regime and landscape level that create 'windows of opportunity' (see Fig. 4). There may be ongoing processes or tensions in the regime to which the new technology can link up. Windows of opportunity can arise because of problems that cannot be met with the available technology, e.g. technical bottlenecks, reverse salients (Hughes, 1987), diminishing returns of existing technology (Freeman and Perez, 1988), presumptive anomalies (Constant, 1980). There may also be changes in markets and user preferences, possibly influenced by wider cultural changes. Or changes may occur in policy agendas, resulting in stricter regulations that create problems for the existing technology. Competition and strategic games between firms may also create opportunities for new technologies. Relative outsiders or firms that have lost market share, may invest in radically new technologies to leapfrog and outmanoeuvre incumbent firms. On top of that, there may be changes at the landscape level that put pressure on the regime and change the selection environment. The key point of the MLP is that transitions come about when niche-internal processes link up with ongoing processes and tensions at the regime and landscape level. This means that existing regimes are not only barriers to be overcome; ongoing regime processes may also provide opportunities.

As the new technology enters mainstream markets it enters a competitive relationship with the established regime. In the fourth phase the new technology replaces the old regime. This is accompanied by wider changes in the socio-technical regime to remove mis-matches that the new technology had with socio-economic dimensions. The new regime may eventually influence wider landscape developments.

An important aspect of the MLP is to do away with simple causality in transitions. There is no simple 'cause' or driver. Co-evolutionary dynamics at the three levels usually remain relatively independent. Transitions take place when dynamics between the different levels become linked and reinforce each other ('circular causality'). So transitions are characterised by non-linearity and uncertainty. By paying attention to co-construction processes at the micro-level, the MLP solves the problem of determinism in macrotheories, such as long-wave theories and Braudel's historical scheme. The MLP also further articulates the notion that alignment and de-alignment processes are important in transitions. It also includes the idea from actor-network theory and long-wave theory that new elements may face a mis-match with the existing system, and have a hard time to break through as long as the existing system is stable and well-aligned. So the MLP integrates several co-evolutionary literatures and gives an answer as to how system innovations come about.

\section{Case-study: from propeller-aircraft to turbojets in aviation systems (1930-1970)}

The aim of this section is to give a brief empirical illustration of the MLP, highlighting co-evolutionary dynamics at different levels and their interactions. This will be done with a case study of the transition in aviation systems, associated with the shift from piston enginepropeller aircraft to jetliners. Much has already been written about aspects of this transition (e.g. Constant, 1980; Edgerton, 1991) and the history of aviation more 


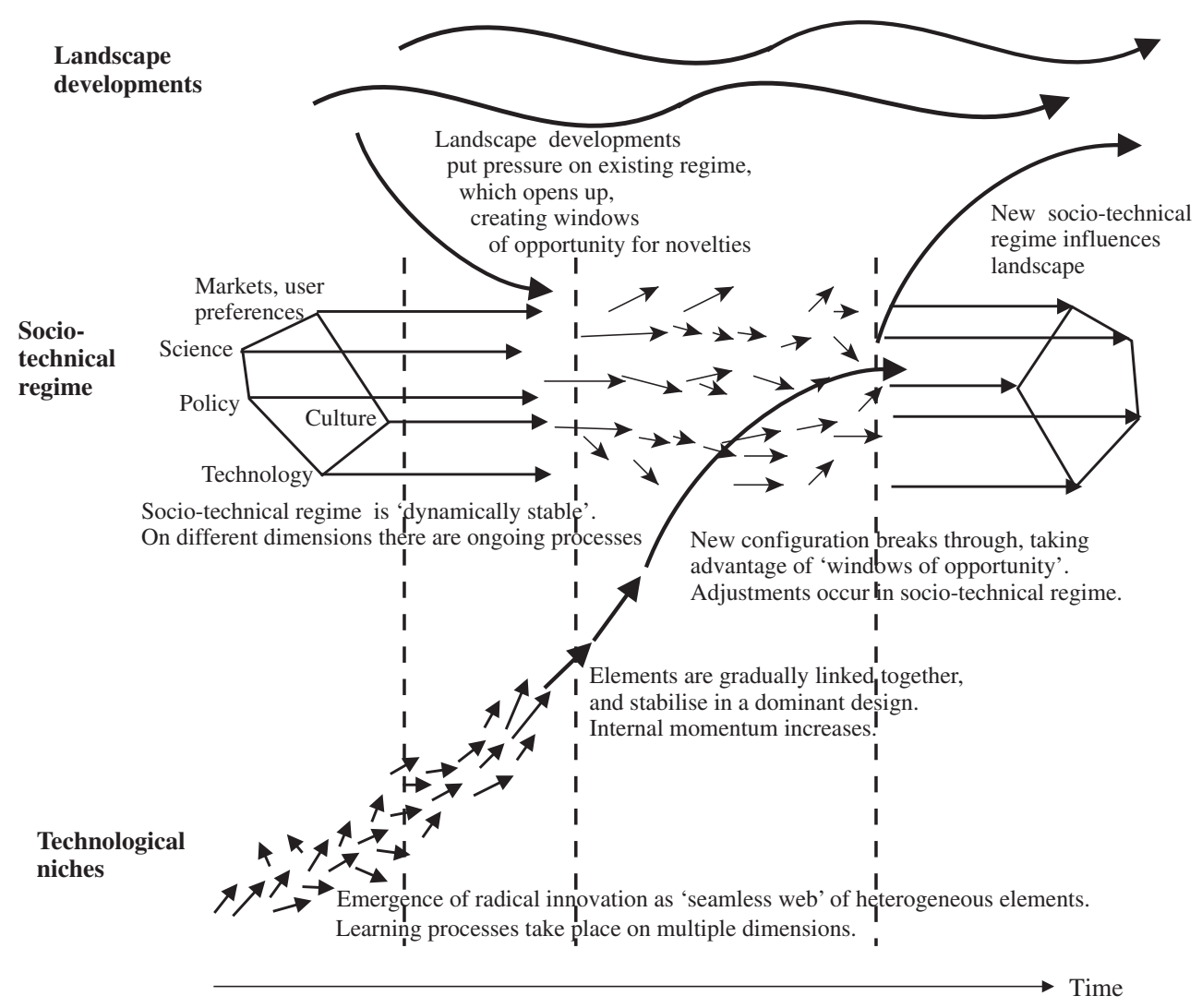

Fig. 4. A dynamic multi-level perspective on system innovations (Geels, 2002, p. 1263).

generally (e.g. Rae, 1968; Todd and Simpson, 1986). The case study is not intended primarily to unveil new historical data, but to illustrate the MLP. Hence, the case study is based on secondary sources, bringing together data on a wide range of topics. It not only describes aircraft and engine technology, but also looks more widely at other aspects of the socio-technical aviation system, such as airports, runways, air traffic control systems (ATCs), regulations, cultural meanings, markets and user groups, and aerodynamic science (see Fig. 1). Relevant actors in this transition are aircraft manufacturers, aero-engine manufacturers, airline companies, scientists, policy makers and defence specialists, passengers and the wider public (see Fig. 3). Aviation consists of two separate, but interpenetrating domains: the military and civil aviation. Four sub-sections describe interactions between niche, regimes and landscape in the following periods: (a) 1930-1940: emergence of jet engines in the military domain, (b) 1940-1950: further development and application of jet engines in the military domain, (c) 1950-1960: hesitant introduction of jet engines in civil aviation, (d) 1960-1970: diffusion of jetliners and wider changes in civil aviation.

\subsection{Stabilisation of aircraft regimes and emergence of jet engines (1930-1940)}

In the 1930s, a wide range of component innovations stabilised into a dominant aircraft design, the DC-3. This was accompanied by the creation of a socio-technical system, e.g. concrete runways, radio-based navigation and ATCs, formal regulations, and markets. Regime actors had strong faith and clear ideas about the direction of future developments. When academic pioneers developed ideas about jet engines in the early 1930s, there was little interest from regime actors. This changed as the threat of war increased, resulting in a small niche for jet engine development.

\subsubsection{Civil aviation regime: stabilisation around the DC-3 as dominant design}

In the 1930s commercial aviation grew rapidly, especially in America (see Fig. 5). Long distances could be flown within the same country, without hassles over sovereign air space, landing rights and passport formalities (Miller and Sawers, 1968, p. 18). The main users were businessmen and politicians (Douglas, 1995, p. 73).

Airline companies demanded better aircraft, i.e. stronger, safer, faster, more fuel-efficient, able to fly longer distances. New aircraft were developed in the early 1930s incorporating component innovations that had emerged in previous years, e.g. all-metal, mono-wing planes, using stressed-skin structures, retractable landing gear, Fowler air flaps, and leading-edge slots. The accumulation of these design changes led to strong improvements in efficiency and streamlining, the so-called 'airframe revolution' (Rae, 1968). These aircraft also incorporated innovations in 

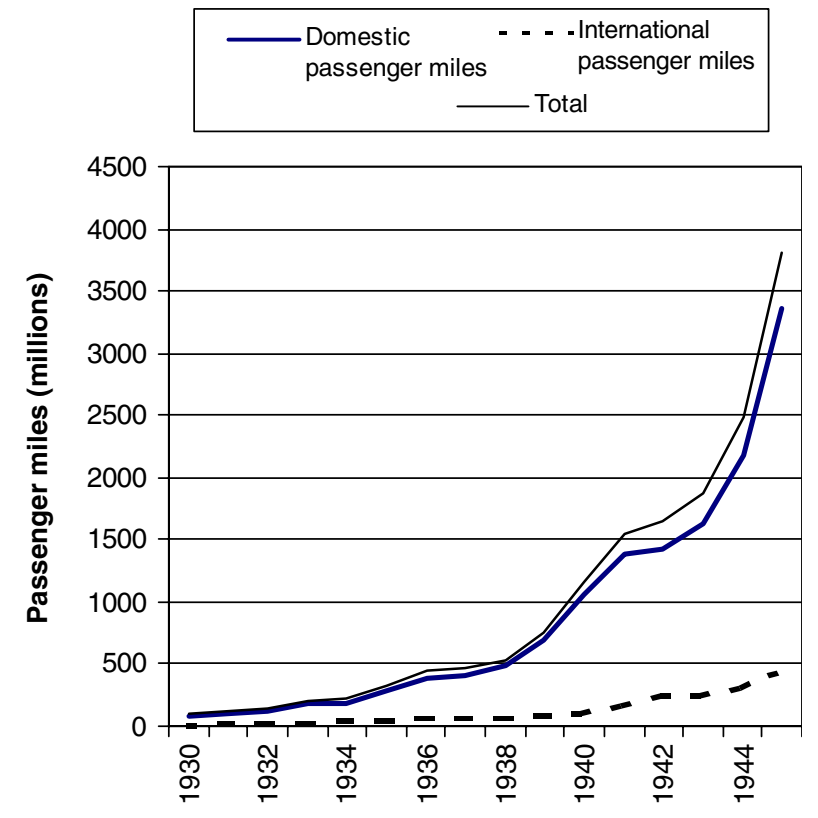

Fig. 5. American civil aviation, 1930-1944 (data from web page of American Air Transport Association).

navigation instruments, e.g. artificial horizon, directional (heading) gyro, altimeters, airspeed indicators, rate of climb indicators. The new aircraft of the 1930s could fly faster and further, because of major performance increases in piston engines, resulting from design improvements in cylinder blocks, pistons, internally cooled valves, fuel innovations, fuel pumps, sealants, lubricants, and controls (Constant, 1980). Notable new planes were the Boeing 247 and the Douglas Commercial Aircraft (DC-1, -2 and -3). The DC-3, introduced in 1936, became the dominant design of civil aviation. By the outbreak of World War II, $80 \%$ of US aircraft were DC-3 (Tushman and Anderson, 1986 , p. 453). The DC-3 could seat 21 passengers, fly at 160-190 mph and had a range of 1000-1500 miles.

With the DC-3, the American network of passenger services was expanded, offering cross-continental services, with 3-4 refuelling stops. Because passengers complained about noise, vibration, turbulence and airsickness, airline companies demanded larger aircraft that could fly higher to reduce turbulence and airsickness. They also wanted greater speed and longer range. In response, aircraft manufacturers designed new four-engine aircraft in the late 1930s, stretching their existing models.

The DC-3 triggered further innovations in the sociotechnical system. Because the aircraft was heavier, it increased wheel pressure on the runway surface. In response, airports increasingly switched from grass fields to concrete runways. This increased the need for precision landing, since pilots had to land right on the runway, while previously they could land on an entire grass field. Hence, a new navigation system was developed, using radio technology. Approaching aircraft received radio signals from radio beacons around the airport, helping the pilot to determine the right flight path (La Porte, 1991).
The crowding of air space posed increasing threats to safety. A major crash in 1935 provided the incentive to regulate the sky, create airways and set up an ATC to monitor airways and direct aircraft. This early ATC-system was manually operated (Field, 1985). The air traffic controller had to keep track of flights within 50 miles of an airport, using a blackboard, a table map of local airways, a telephone and teletype (Fig. 6). Aircraft emitted radio signals to radio beacons on the ground. With three stations it was possible to use time differences between the arrivals of signals to calculate the position of the aircraft. On a map flight paths of different aircraft were represented by small 'toys'. The ATC centre communicated flight paths with the control tower, which directed pilots via radio.

The late 1930s also saw a general tightening-up of formal rules and regulations. The concept of 'controlled airspace' was developed in 1936, specifying airways. The Civil Aeronautics Act (1938) provided further codification and created the Civil Aeronautics Authority (CAA) with power to regulate airline tariffs, airmail rates, mergers, and airline routes. Air traffic controllers were given more authority to give binding directions for landing routes. Pilots were soon filing flight plans and had them reviewed prior to takeoff to prevent collision (Heppenheimer, 1995).

There were two relatively minor problems with piston engine-propeller aircraft. The first was the high-altitude problem. Because air gets thinner at greater heights, propellers have less grip and engines suffer a lack of oxygen, reducing the efficiency of the combustion process. The second was the high-speed problem. When the speed of propeller tips approached the sound barrier, a compressibility bubble occurred that substantially increased drag and decreased speed.

There were strong beliefs in the aviation regime that both problems could be solved with incremental innovations. One response to the altitude problem was the development of variable-pitch propellers, making it possible to adjust the propeller-pitch for different speeds, altitudes, and loads. A response to the engine-altitude problem was the adoption of superchargers. By compressing air at high altitude, piston engine power could be maintained. While superchargers helped to increase the altitude ceiling, they did not entirely solve the high altitude-problem.

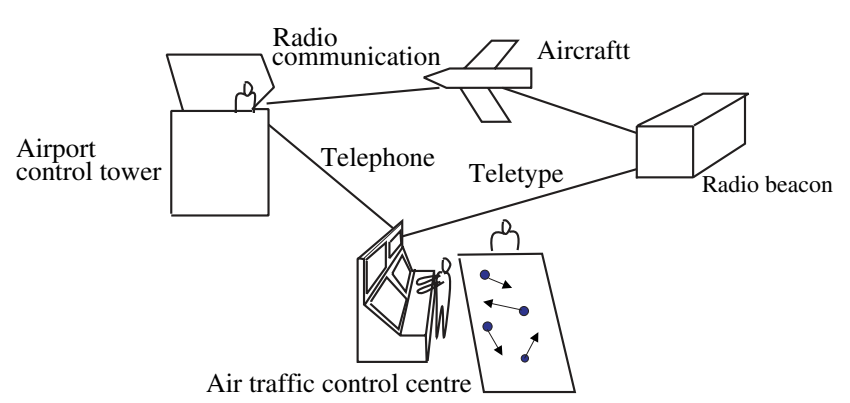

Fig. 6. First generation air traffic control system (Gilbert, 1973, p. 97). 


\subsubsection{Military aviation regime: war preparations and $R \& D$ strategies}

In the second-half of the 1930s, a major landscape change, the approach of war, led to rearmament programmes in Germany and Britain. Hitler quickly build-up an air force with a focus on tactical dive-bombers and fighter aircraft. The German Air Ministry (RLM) was also interested in new propulsion systems, such as turbojets and turboprop engines. British rearmament focused on defensive fighters and bombers (Edgerton, 1991). Britain developed two new fighters: the Hurricane and the Spitfire (speed around $565 \mathrm{~km} / \mathrm{h}$ ). R\&D programs were set up in three fields: radar, fighters and aero-engines (Nahum, 1997). In the late 1930s, Britain developed radar technology (Eldridge, 2000, p. 5). By the outbreak of war a network of radar stations along the British coast was in place. Prior to radar, interception of bombers relied on 'standing patrols' of fighter aircraft, already flying in the air. These patrols were relieved periodically as their fuel became exhausted. Hence, low fuel consumption used to be a guiding principle in the development of aero-engines. Radar technology led to a change defence tactics. Fighters could stay on the ground until enemies were spotted by radar. Fighters then had to climb quickly to great heights from which to intercept approaching aircraft. Hence, the guiding principle shifted from fuel efficiency to engine power in order to give good climb rates (Nahum, 1997). While European countries were preparing for war, America was in a complacent mood, paying little attention to modernisation of its air fleet.

\subsubsection{Niche developments: emergence of jet engine as co- construction process}

The high-altitude and high-speed problems triggered engineers and scientists to work on alternative technologies. One alternative was the turboprop, using the rotational power of a gas turbine to spin a shaft that powered a propeller. The turboprop was seriously studied, especially by Dr. Griffith at the British Royal Aircraft Establishment (RAE). In 1929 Griffith described the contours of a turboprop engine in a research report for his superiors. But there was no money for an expensive development and testing project and the project was shelved (Edgerton, 1991). The aeronautical community felt that the option of gas turbine propulsion had been explored and decisively rejected.

While the negative opinion about the gas turbine hardened amongst regime actors, science breathed new life into it. Ideas about turbojets emerged independently from the work of Frank Whittle in Britain, Hans von Ohain and Herbert Wagner in Germany. These men were all relative outsiders to the aviation regime, young and with an academic background in aerodynamic science. The improvements in airframes made these aerodynamic scientists ponder the high-speed problem. Assuming that improvements in airframes would continue, they reasoned that near-sonic speeds would become possible in the future.
Theories and experiments with supersonic airflow showed that turbulence occurred at high speeds, leading to a compressibility bubble around propeller tips resulting in increased drag. This meant that propellers would form a future obstacle to achieve sonic speeds (Constant, 1980). Hence, they searched for different propulsion systems. Their innovativeness was to take a different view at the gas turbine, focusing not on its rotational power, but on the thrust of exhaust gases. The jet stream from gas turbine combustion might be able to deliver sufficient propulsion to power aircraft.

To develop, test and realise their ideas, the challenge for the turbojet pioneers was to build a socio-technical network. They had to align and co-construct different elements, such as sponsors and finance, technical facilities, technical skills and theoretical knowledge. In trying to build a protective social network, the pioneers travelled between domains such as policy makers (Air Ministry, Defence specialists), business (aircraft manufacturers), law (to secure patents), and science (to further develop their ideas). But initially, the turbojet pioneers had difficulty to find interest from the aeronautic community. Regime actors had little interest in alternative engines, because progress in the performance of piston engines and propellers had been strong, and there was widespread belief that this progress would continue. So jet engines faced a mis-match with strong faith by regime actors in existing aircraft.

Whittle was the first to develop ideas about jet engines, acquiring a patent in 1930. The same year, he spoke with the Air Ministry, but officials there described his ideas as 'impractical'. Whittle then approached a number of aeroengine firms, but they also showed no interest. In 1935 , Whittle and two friends formed a small company to develop the engine themselves (Constant, 1980). At Gottingen University, Von Ohain calculated that the greater fuel consumption of the turbojet could be compensated by its lighter weight compared to a piston engine and propeller. He thought that the engine's high thrust/weight ratio would make it suitable for fighter aircraft. In 1934, he constructed a small demonstration engine at his own expense. But the combustors did not function properly and the engine never really ran (Constant, 1980). At the Technical University of Berlin, Wagner concluded in 1937 that, without propeller, the gas turbine could result in a light engine, with acceptable efficiency at high speeds and altitudes. He sought external support to develop the idea.

A major landscape change, the approach of war, created a window of opportunity for the jet engine pioneers. The expansion of military R\&D budgets created more resources for innovative projects and more openness for new ideas. Military planners and R\&D managers in Britain and Germany became more interested in high-performance aero-engines. Whittle, Von Ohain, and Wagner were able to build a support network for the further development of their ideas. The Aeronautical Research Council (ARC) 
gave Whittle's company a small contract in 1937 to develop and test his jet engine ideas. In 1938 the Whittle engine reached $13.000 \mathrm{rpm}$, measuring a thrust of $480 \mathrm{lb}$ (Gunston, 1997, p. 129). This demonstrated its technical feasibility. The Air Ministry sponsored a new project, and in mid-1939 a high profile test was witnessed by government representatives, convincing the Air Ministry of the jet's potential (Constant, 1980). The government increased R\&D funding for the jet engine, leading to a proliferation of turbojet projects. The government sidelined Whittle and gave most development projects to existing aero-engine companies (e.g. Metropolitan-Vickers, De Havilland, Rolls Royce). In Germany Wagner teamed up with Junkers aircraft and got an engine tested in 1938. Von Ohain linked up with Heinkel Aircraft in 1936, and a prototype first ran in 1937, giving a thrust of $551 \mathrm{lb}$ (Gunston, 1997, p. 125). In 1939, an improved version produced a static thrust of $992 \mathrm{lb}$, and Heinkel authorised construction of a jet aircraft. The world's first jet aircraft flew on 27 August, 1939, reaching a speed of $450 \mathrm{~km} / \mathrm{h}$. Although the engine's combustion chamber overheated, the practicality of jet-powered flight was proven. The German Air Ministry increased resources for development projects, involving major German aeroengine manufacturers: Daimler-Benz, Junkers Motors, B.M.W. and Bramo.

In sum, by the late 1930s the pioneering ideas about jet engines had been transformed into a technological niche. There was a network of actors willing to invest time, money and personnel into jet engine development, because they shared the expectation that it had good potential. The resources and protection provided space for technical learning processes. While the technical feasibility of jet engines was demonstrated, many problems and bottlenecks still had to be solved. Researchers and engineers were venturing into unknown areas of high temperatures, high airflow speeds, supersonic aerodynamics, and high tensile material stress. Design was a 'dark art', in which designers used crude empirical formulae, slide-rules and tables (Constant, 1980). With regard to combustion, design questions focused on the shape of the combustion chamber, fuel injection, mixing of air and fuel, combustion control. The high temperatures often made existing materials brittle. Material innovations were called for, leading to experiments with different metal alloys. Turbine blades also created design challenges, for instance regarding their shape (they should absorb energy from the exhaust gas, but not too much). The blades should also be strong enough to withstand shockwaves when the gas flow reached the speed of sound (Gunston, 1997, p. 42). Blades should also withstand high temperatures and severe centrifugal stress caused by high-speed rotation. With regard to compressors, there were two basic design options: centrifugal flow compressor and axial flow compressor. Both types had advantages and disadvantages. Although the axial flow compressor was easier in its basic design, it was were difficult to construct with the materials and techniques of the late 1930s. Axial flow compressors were prone to failure, because of vibration problems of radial blades. Turbojet pioneers such as Whittle and Von Ohain chose the centrifugal type, which was cheaper, more robust, and more predictable in behaviour (Gunston, 1997, p. 17). Although the design problems were challenging, it also meant that there was ample scope for performance improvement.

\subsection{Breakthrough of turbojets in the military domain and expansion of civil aviation (1940-1950)}

\subsubsection{Military aviation regime}

Early in the war, Britain was under attack from German bombers, and needed high-performance interceptor fighters for its defence. Hence, early in the war Britain invested substantially in turbojet projects (Edgerton, 1991). Later in the war Allied forces acquired air superiority and took the air battle to Germany, using bombers to attack militaryindustrial facilities. By then Britain needed bombers, while Germany needed interceptor fighters. Hence, Britain invested less in turbojets by the end of the war and Germany more. During the war, production of aircraft increased strongly, especially on the Allied side (Zeitlin, 1995). The 1942 Lyttleton Agreement stated that Britain would focus on warplanes, specifically bombers and fighters, while America would be responsible for heavy bombers and transport aircraft (Benson, 2000, p. 29). The American Army sponsored the development of pre-war designs of four-engine aircraft for military uses.

\subsubsection{The breakthrough of jet engines in the niche of interceptor fighters}

Early jet engines produced much thrust, but had high fuel consumption, limiting their range. Hence, an appropriate niche for the jet engine was the interceptor fighter. To increase thrust, combustion temperature was increased, something that required stronger and heat-resistant materials. Nickel-chromium alloys were developed to strengthen the combustion chamber and turbine blades. By the end of the war, jet engines produced between $2000-4000 \mathrm{lb}$ of thrust. More powerful jet engines were under development, e.g. the Rolls Royce Nene RB.41, designed to give $5000 \mathrm{lb}$ thrust (Gunston, 1997, p. 136).

During the war, German engineers increasingly focused on axial flow jet engines, because they had a smaller frontal area and could be more easily fitted under aircraft wings. Messerschmitt's engineers developed a revolutionary new airframe with swept-back wings, enabling the aircraft to overcome shock waves and reach very high speeds. The Me-262 first flew on July 1942, outperforming all other fighters, with its high speed of nearly $525 \mathrm{mph}(844 \mathrm{~km} / \mathrm{h})$. Only 1400 Me-262 aircraft were produced, but their performance impressed the aviation community. In Britain, the first test flight with a jet aircraft took place in May 1941 , reaching a speed of $480 \mathrm{~km} / \mathrm{h}$. But as the war progressed, British aviation tactics shifted from interceptor fighters to bombers. Although there was less need for jet 
fighters, the British Gloster Meteor I went into service in May 1944 (Edgerton, 1991). American engineers also developed jet engines, after they acquired turbojet knowledge, as part of a knowledge sharing arrangement with Britain in 1941. Defense contracts were given to three steam-turbine firms (Westinghouse, Allis-Chalmers, and General Electric) to develop both centrifugal- and axialflow jet engines (Gunston, 1997, p. 143). GE became one of the leading jet engine manufacturers by the end of the war. Traditional American aero-engine manufacturers (Pratt \& Whitney, Wright Aeronautical) were deliberately excluded from turbojet development. In post-war years, Pratt and Whitney was able to make the transition to jet engines. Although America did not produce jet fighters, it developed some of the most powerful jet engines by the end of the war. The USSR also acquired turbojet knowledge as it overran Germany.

By the end of the war, jet engines were seen as an important direction of future development for fighter aircraft where thrust and speed were important. Britain, with its shattered economy and empty treasury, placed the development of jet fighters on the backburner and focused on commercial ventures such as civilian jetliners (Engel, 2000). America, convinced of the importance of air power, developed the F-86 Sabre jet fighter in 1947 (speed of $1225 \mathrm{~km} / \mathrm{h}$ ). But in terms of overall numbers, American production of jet fighters was moderate before 1950. The unexpected confrontation during the Korean War (1950-1953) with the Russian MiG-15 jet fighter was a shock, because it performed at least as good as the American F-86 Sabre. Hence, America stepped up the development of jet fighters and jet engines, gradually overtaking Britain's lead in turbojet development. America increasingly tended towards the axial turbojet, which had a smaller frontal area, was more compact, but also was more complicated (Dawson, 1995, p. 133). As problems in the axial jet engine were solved through component innovations, it became the dominant design in the late 1940s.

\subsubsection{The civil aviation regime: international rivalry and expansion}

Commercial aviation in Europe strongly declined during World War II, but in America it continued to grow (Fig. 5). The socio-technical system was further developed, expanded and stabilised. But there was also a tension that provided a window of opportunity for jetliners. Already during the war, a rivalry between Britain and America emerged about the future of post-war commercial aviation (Benson, 2000). Because American wartime production focused on heavy bombers and transport aircraft, American manufacturers would be well placed to produce large civilian aircraft in the post-war period, enabling them to dominate the world market. To counter this expected hegemony, the British government set up the Brabazon Committee in 1942 to develop plans for post-war aviation (Edgerton, 1991). The Committee recommended a leapfrog strategy, using Britain's leading edge technolo- gies for large-scale civilian projects. One of the proposed projects was a civil jetliner, the Comet, exploiting Britain's advanced turbojet technology. The project would be realised after the war.

When the war ended, the American government dumped surplus aircraft on the commercial market for sometimes as little as $\$ 90.000$ (Heppenheimer, 1995, p. 114). This enabled the entry of small airline companies with cheaply operated aircraft. In 1949, this led to a price war between these non-scheduled companies and the major airlines, resulting in ultra-low fares (Heppenheimer, 1995, p. 127). These price reductions stimulated the expansion of domestic aviation, which, in turn, created space for the use of four-engine aircraft whose performance had been demonstrated during the war. These bigger aircraft offered more comfort and had longer range. Non-stop coast-tocoast service started in March 1946 with the four-engine Constellation. International passenger transport also expanded. With four-engine aircraft, global travel became a reality (Bilstein, 1995). In 1945, airline companies created a cartel organisation, the International Air Transport Association (IATA), to limit competition and keep international fares artificially high.

\subsection{Hesitant introduction of jetliners in civil aviation (1950-1960)}

\subsubsection{Civil aviation regime}

American domestic air travel continued to grow rapidly in the 1950s and more people began to see flying as a 'normal' means of transport (see Fig. 7). In 1951, airline passengers exceeded train passengers for the first time. In 1956 more travellers between America and Europe went by aircraft than by steamship (Bilstein, 1995, p. 105).

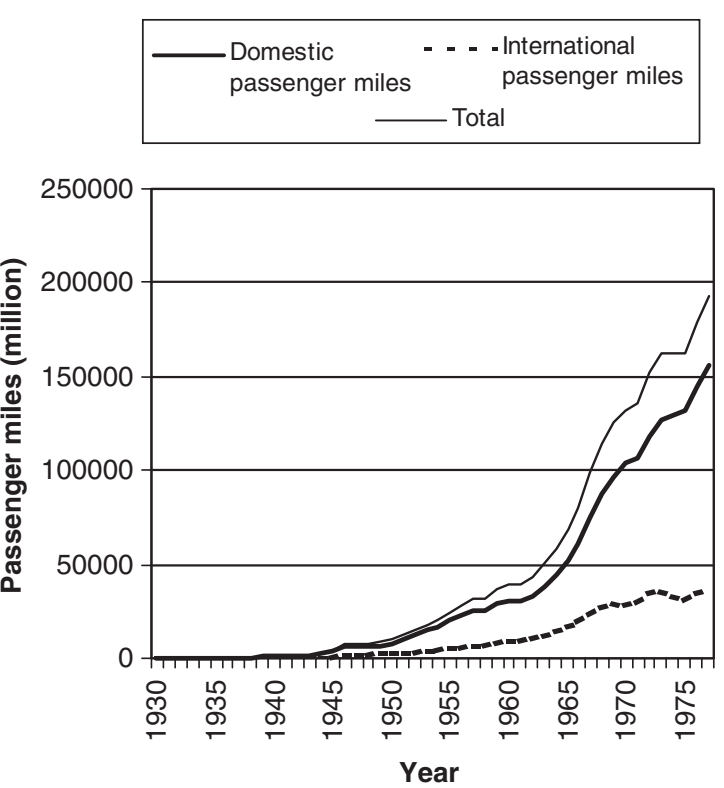

Fig. 7. American civil aviation, domestic and international, 1930-1977 (data from web page of the American Air Transport Association). 
Expanding markets created space for further stretching of existing aircraft designs, leading to the Super Constellation (1950) and DC-7 (1953). The DC-7 had enough range to offer non-stop transatlantic service, finding use in the expanding international passenger transport market. In 1952 IATA introduced Tourist Class tickets on transatlantic routes, which were approximately $32 \%$ cheaper (Dierikx and Bouwens, 1997, p. 81). The term Tourist Class indicates that airline companies were beginning to reorient themselves towards a new consumer group: the leisure traveller.

The four-engine aircraft were fitted with pressurised cabins, allowing them to fly at higher altitudes with less turbulence problems and more comfort. But the maximum altitude was limited because of high-altitude problems. There was a tension between piston power, altitude and passenger comfort.

By the mid-1950s, skies were getting more crowded with aircraft and pressure on airports was increasing. In June 1956, two aircraft collided in flight, killing 128 people (Heppenheimer, 1995, p. 178). This accident pointed to the lack of long-range radar, which could track and space aircraft continuously as they flew through airways. In response, Congress passed the Federal Aviation Act in 1958, creating a new regulatory agency, the Federal Aviation Agency (FAA). The FAA was charged with establishing an ATC to maintain safe separation of commercial aircraft through all phases of flight. To improve safety, navigation, control and communication an increasing number of electronic instruments entered the aircraft, establishing avionics as a rapidly expanding sector (Fishbein, 1995).

Another tension in the aviation regime was formed by competition and rivalry. Because aviation was a rapidly growing market, actors were jockeying for position in strategic games. One strategic game was between Britain and America. Another strategic game was between Douglas Aircraft, the dominant aircraft producer in civil aviation, and Boeing, who was strong in the military market, but relatively weak in civil aircraft. Because cruise missiles were expected to replace strategic bombers in the future, Boeing aimed to diversify into civilian markets (Heppenheimer, 1995). A third strategic game was between airline companies, jockeying for position in the passenger market. Pan American Airlines, strong in international passenger transport, positioned itself as an innovative company, ready to explore new possibilities, routes and aircraft technologies. These multiple strategic games in the aviation regime created windows of opportunity through which jet engines entered civil aviation (see below).

Another tension in the aviation regime of the late 1940s and early 1950s was uncertainty about future propulsion systems. Improved compound piston engines, delivering up to $20 \%$ more power, were introduced in 1950 in bombers and commercial planes (Heppenheimer, 1995, p. 128). The turboprop engine was developed in Britain after the war, as one way to leapfrog American dominance in civil aviation.
The turboprop was used in the Vickers Viscount (1948), a popular civil aircraft in Europe, where many airline companies flew short- and medium-range routes. The turboprop seemed to offer the best of two worlds: higher speed than piston engine-aircraft and better fuel economy than jets (Gardiner, 1984, p. 130). The third engine was the jet engine, with high thrust and high fuel consumption. For passenger aircraft high fuel costs of jet engines could be a problem, and for bombers limited range could be a problem. The uncertainty about engine technology formed an important arena for the strategic games. Incumbent actors stuck with established piston engines and adopted a wait-and-see attitude. For relative outsiders (Britain, Boeing) and innovative actors (e.g. Pan Am) the new engines formed an opportunity for a leapfrog strategy. But this strategy also entailed risks, because of uncertainties related to the new technologies. Boeing's strategy to the civil jetliner was indirect, proceeding via the niche of jet bombers. Britain's strategy was to go directly for jetliners. Both routes are described below.

\subsubsection{Niche developments in bombers: breakthrough of jet engines}

Jet engines were initially rejected for bombers, because of their high fuel consumption. When Boeing engineers made plans for a new long-range, heavy bomber (the B-52), they first considered turboprops (Heppenheimer, 1995). But a complementary innovation, refuelling in the air, changed the perception in favour of jet engines: refuelling in the air. Because this made high fuel consumption less of problem, Boeing engineers opted for jet propulsion in 1948 to power the B-52. This was possible, because the performance of jet engines continued to be improved. Pratt and Whitney produced powerful engines, such as the J-42 (1948), producing $8750 \mathrm{lb}$ thrust with afterburner, and the J-57 (1952), producing 10,000 lbs (Gunston, 1997). Especially the $\mathrm{J}-57$ engine came to power very large aircraft such as the B-52 bomber, which entered service in 1952, and the civilian Boeing 707 and DC-8. Jet engines came to be seen as powerful all-purpose propulsion engines.

For refuelling in the air, tanker aircraft were needed that flew as fast as jet bombers. In 1952, Boeing began designing a jet tanker, on the basis of an explicit dual-use strategy, hoping to sell redesigned jet tankers as jetliners to airline companies.

\subsubsection{Niche developments in civil aviation: hesitant introduction and strategic games}

The jet engine was slow to enter American civilian aviation. Airline companies were hesitant about fuel costs. There were also uncertainties about the durability of jet engines, operating at high temperature and stress. Experience with jet fighters did not take away the doubt, because civil aircraft were used on a more continuous basis, every day, all year round. There was also a mis-match with the length of runways. Since jet engines are relatively inefficient at low speeds, long runways are needed for take-off. And 
since turbojets were developed in the military domain, there was a degree of the Not Invented Here syndrome (Gardiner, 1984, p. 130).

Following the Brabazon plan, the British government sponsored De Havilland, an aircraft manufacturer, to develop the Comet. Test flights were held in 1949, and the first civil jetliner entered commercial service in 1952 with the British Overseas Airways Corporation (BOAC). Because BOAC was a state-sponsored company, it would not matter if the Comet was expensive in operation. The Comet amazed the world with its performance, and was popular with customers, because it provided a smooth ride, high above the weather, reducing turbulence and increasing flight comfort. The Comet was also faster, raising speeds to 470-500 mph. Its high speed and modern image appealed to passengers. But operating costs were nearly three times as much as the piston engine DC-6. On the other hand, it flew with nearly every seat filled, and BOAC found that it was actually making money (Heppenheimer, 1995, p. 156). In 1952 and 1953, many airline companies, including American ones, placed orders for the Comet. But in 1954 the Comet dream was torn apart by a string of fatal accidents, caused by metal fatigue, an unfamiliar phenomenon at the time.

The Comet showed that jetliners were technically feasible, and that the public loved them. It was a wakeup call for American airline companies. In October 1952, Pan American ordered three Comet planes from De Havilland. After the Comet accidents, Pan Am turned to Boeing and Douglas Aircraft. Douglas Aircraft had made preliminary designs for jetliners (DC-8), but Boeing already had a prototype jet tanker, the Dash-80. In May 1954, the Dash-80 convinced the Air Force to order 29 jet tankers. This gave Boeing financial space to convert the aircraft design to the civilian Boeing 707. In October 1955, Pan Am ordered 20 Boeing 707s and 25 DC-8s. Once Pan Am had crossed the thresh-hold, other airline companies followed quickly, for fear of being left behind, thus creating a bandwagon effect. Concerns about economic feasibility and mis-matches with the regime are visible in a comment from the president of Delta Airlines in 1956:

We are buying airplanes that haven't been fully designed, with millions of dollars we don't have. We are going to operate them off airports that are too small, in an air traffic control system that is too slow, and we must fill them with more passengers than we have ever carried before (cited in Heppenheimer, 1995, p. 170).

In the race for orders Boeing proved successful, and by the end of 1956 the Boeing 707 outsold the DC- 8 by three to one. The 707 entered service in 1958, raising cruising speeds to $550-600 \mathrm{mph}$, accommodating up to 181 passengers.

\subsection{Replacement of piston-engines and wider impacts on aviation systems (1960-1970)}

Civil jetliners were first introduced in the long-distance market niche, where their advantage of high speed made the greatest difference. Their diffusion to other markets and routes was gradual and required many changes in the socio-technical system, e.g. in runways, ATCs, pilot skills, tariffs, marketing and passenger groups. This is described below.

In long-distance markets, jetliners rapidly replaced fourengine piston aircraft. But for short distances, the piston engine remained competitive until the mid-1960s when turboprops gradually replaced them. For medium-distance routes turboprops were initially more efficient than turbojets and piston engine. But jetliners were further improved and downscaled, leading for example to the French Caravelle (1959) and the Boeing 727 (1964). During the 1960s turboprops progressively lost market shares to jetliners in the medium-range market segment (Bonaccorsi and Giuri, 2000).

But the diffusion trajectory was not straightforward. Initially, airline companies were actually losing money with jetliners, and overall profits decreased and were sometimes negative (see Table 1). One reason for lower profits were high purchase costs. Another reason was that larger aircraft led to a decrease in the load factor from $62.2 \%$ in 1955 to $56.1 \%$ in 1965 (Tillinghast, 1966).

But user experience in subsequent years unexpectedly showed that jetliners could save costs on several dimensions. Although jet engines used much fuel at speeds below $400 \mathrm{mph}$, their efficiency increased at higher speeds. Jetliners also flew at higher altitudes, with less drag. Jets could use cheaper fuel, which helped to offset the effects of higher fuel consumption (Miller and Sawers, 1968, p. 187). Furthermore, the development of fan-type jet engines with high by-pass ratios increased their fuel efficiency. Another drop in operating costs came from economies of scale. The same number of crew could serve more passengers. And the higher speed meant that less crew was needed on long journeys. The higher speed also meant that more flights per year could be made, increasing its yearly productivity. Another source of savings was maintenance costs (Miller and Sawers, 1968, p. 209). Because jet engines had less moving parts than piston engines, they had less breakdowns and the time interval for overhaul was stretched from 2000 to $2500 \mathrm{~h}$ of service for piston engines to as long as $8000 \mathrm{~h}$ for jet engines (Rosenberg, 1986, p. 25). Another change, in response to decreasing load factors, was that airline companies tried to attract new user groups with lower airfares and new marketing strategies. They increasingly targeted the leisure market, emphasising tourism and exotic trips in their marketing. To stimulate international demand, IATA airline companies introduced the Economy Class in 1958, as a new cheap ticket $20 \%$ below Tourist Class (Dierikx and Bouwens, 1997, p. 83). As a result of these changes, both domestic and international aviation 
Table 1

Operating profits from carriers of the International Civil Aviation Organization (Tillinghast, 1966, p. 3)

\begin{tabular}{|c|c|c|c|c|c|c|c|c|c|c|c|}
\hline Year & 1955 & 1956 & 1957 & 1958 & 1959 & 1960 & 1961 & 1962 & 1963 & 1964 & 1965 \\
\hline Operating revenues (billion \$) & 3.0 & 3.5 & 4.0 & 4.1 & 4.8 & 5.4 & 5.8 & 6.6 & 7.2 & 8.2 & 9.3 \\
\hline Operating profits (million \$) & 78 & 84 & -41 & 15 & 105 & 70 & -118 & 97 & 326 & 601 & 890 \\
\hline$\%$ & 2.6 & 2.4 & -1.0 & 0.3 & 2.1 & 1.3 & -2.0 & 1.5 & 4.5 & 7.3 & 9.6 \\
\hline
\end{tabular}

experienced accelerated grow in the mid-1960s (see Fig. 7). By 1963 a period of profitable operations began in the jet age.

Jetliners also triggered further changes in the aviation system. They needed longer runways for take-off, because of jet engine's relative inefficiency at low speeds. While piston-engine DC-7s needed 7000 feet, a fully loaded Boeing 707 needed 11.500 feet for take-off (Heppenheimer, 1995 , p. 186). Jetliners also required that pilots, accustomed to piston-engine airplanes, had to be retrained. The piston-engine airplanes, with their straight wings, normally sat on their landing gear at a slightly positive angle of attack. When they reached take-off speed, they pretty much flew themselves off the ground. The jetliners, with their swept wings, not only had much higher take-off speeds, but also had to be powerfully 'rotated' (pulled up with their elevators) at take-off speed. Pilots had to learn to fly 'by the numbers'. ${ }^{2}$ Adjustments were also made in air traffic control. The main stress on ATC-systems arose from the increasing difference in aircraft speeds, ranging from $400 \mathrm{~km} / \mathrm{h}$ for piston engine aircraft to $950 \mathrm{~km} / \mathrm{h}$ for jetliners. The control of airspace around airports had to be faster, more precise and cover larger distances. Because of the faster approach of jets, airports installed long-range radar, allowing aircraft monitoring over greater distances. This complicated the task of air traffic controllers, who were still calculating positions of aircraft by hand. To deal with the increasing volume of bookkeeping functions and data-processing requirements, computers were introduced in ATC-systems (Gilbert, 1973, pp. 98-99). Jetliners also led to protests from local residents near airports, because of increased noise problems. There were political debates about noise regulation and airports implemented noise limits for aircraft (Smith, 1989, pp. 20-21). But noise problems continued to create problems in subsequent years, as aviation expanded. A technical innovation that enabled flying for the masses, was the Boeing 747 (1969). The wide body aircraft represented a jump in passenger numbers (450-500 passengers) and speed $(640 \mathrm{mph})$. The combination of fuel-efficient turbofans and scale economies allowed a $30 \%$ reduction in operating cost per seat mile (Hopps, 1978). With lower tariffs and powerful, longdistance aircraft, aviation truly became a mass phenomenon in the 1970s.

\footnotetext{
${ }^{2}$ From personal communication with Edward Constant on 10-7-2001.
}

\section{Conclusion}

This article showed how transitions in socio-technical systems can be studied not only as technological discontinuities, but as long-run co-evolution processes that also involve changes in markets, user groups, infrastructure, science, culture and regulation. The literature review showed that different levels of co-evolution can be distinguished. At the micro-level of emerging innovations, this takes the form of co-construction and mutual shaping between heterogeneous elements. At the meso-level, coevolution takes the form of inter-related activities of social groups, separated by permeable boundaries, leading to multiple streams and trajectories that influence each other. At the macro-level, co-evolution is understood as slowchanging social, cultural, economic, technological and environmental developments, that form a contextual backdrop for dynamics at micro- and meso-level. These three levels of co-evolutionary dynamics were integrated in an MLP on transitions, and rephrased in evolutionary terms as niche, regime and landscape. The main point of this perspective was that transitions start in niches, where co-construction dynamics are played out. Further breakthrough and system innovation are the result of interactions between co-evolutionary dynamics at multiple levels.

The empirical case study clearly demonstrated the importance of interactions between niche, regime and landscape. The turbojet pioneers developed their ideas building on regime developments, such as aerodynamic science about supersonic airflow, turbulence and a compressibility bubble at high speeds. They also build on the airframe revolution of the early 1930s, assuming that improvements in aircraft streamlining would continue. This led them to conclude that propellers would form a barrier to higher speeds and that alternative propulsion methods would be needed. The transformation of ideas about jet engines into prototypes took place in the particular niche of interception fighters. The creation of this niche was stimulated by a major landscape change, the approach of World War II. Before this change, turbojet proponents had great difficulty to build a support network, because there was a mis-match with prevailing beliefs in the regime. Co-construction in the niche took the form of aligning elements such as sponsors, finance, technical facilities, patents, skills and theoretical knowledge. To build a 'seamless web', turbojet proponents travelled between domains such as policy, business, law, and science. There was no strong co-construction on the user side, since 
fighter pilots already existed. But dynamics on the user side were more than simple adoption, because jet fighters became part of a new defence strategy, where aircraft would stay on the ground until enemy aircraft were spotted by radar. After the Second World War, jet engines were further developed and implemented in fighters. This development was accelerated by another landscape development, the Korean War. In civil aviation the breakthrough of jet engines in the 1950s depended on several ongoing dynamics and tensions in the existing regime. One tension was the high-altitude problem. Especially on longdistance flights, a growing market niche, passengers demanded more comfort and less turbulence (to reduce air sickness). This could be achieved by flying at high altitudes, above the weather. But there were technical limits to the operation of piston engine-propeller aircraft at high altitudes, creating a window of opportunity for jetliners. Several strategic games between regime actors were also crucial for the breakthrough of jetliners. There was competition between Britain and America, between Boeing and Douglas Aircraft and between airline companies, with Pan American advocating itself as innovative frontline airliner. Engine technology was an important arena where these strategic games were played out, especially when new engines appeared in the late 1940s and early 1950s (improved piston engines, jet engines, turboprops). These strategic games in the regime provided crucial windows of opportunity for the breakthrough of jet engines. Relative outsiders (Britain and Boeing) supported jet engines as part of a leapfrog strategy, while Pan Am adopted jetliners to reinforce its image and attract customers that were sensitive to jetliners' modern appeal.

Co-evolution at the landscape level was not strong in the case study. The landscape level mainly played a role in the form of wars. But at the regime level, co-evolution was clearly visible. There was a strong interaction between technology and markets. As markets grew, there was demand for new aircraft that were safer, stronger, bigger, faster and could fly longer distances. These aircraft, in turn, opened up new routes and attracted more passengers, which created new demands for better aircraft. There were also strong interactions between heavier aircraft and runways, between growing markets, denser air space, regulations and ATCs, and between markets, technologies and strategic games. Some of these co-evolutionary dynamics preceded jetliners and created windows of opportunity (see above); others followed it, leading to adjustments in aviation systems in the 1950s and 1960s.

The conclusion is that the case study confirms the idea of the MLP that transitions come about because of linkages between co-evolutionary dynamics at multiple levels. This emphasis on linkages is a useful antidote against the idea that transitions come about only because of price/ performance improvements. Transitions are not caused by a change in a single aspect, but by the interplay of many aspects and actors. The added value of the MLP is that it provides not just an evolutionary economic analysis of technological change, but deals with the long-run evolution of technology and the socio-economic system.

\section{Acknowledgement}

I gratefully acknowledge financial support from the Dutch Knowledge Network on System Innovation (KSI).

\section{References}

Benson, E., 2000. Suspicious Allies: wartime aviation developments and the Anglo-American International Airline Rivalry, 1939-1945. History and Technology 17, 21-42.

Bertels, K., 1973. Geschiedenis Tussen Struktuur en Evenement: Een Methodologies en Wijsgerig Onderzoek. ('History Between Structure and Event: A Methodological and Philosophical Investigation'). Wetenschappelijke Uitgeverij BV, Amsterdam.

Bijker, W.E., Law, J. (Eds.), 1992. Shaping Technology/Building Society: Studies in Sociotechnical Change. The MIT Press, Cambridge, MA.

Bilstein, R.E., 1995. Air travel and the travelling public: the American experience, 1920-1970. In: Trimble, W.D. (Ed.), From Airships To Airbus: The History of Civil and Commercial Aviation. Pioneers and Operations, vol. 2. Smithsonian Institution Press, Washington, London.

Bonaccorsi, A., Giuri, P., 2000. When shakeout doesn't occur: the evolution of the turboprop engine industry. Research Policy 29, 847-870.

Braudel, F., 1958. Histoire et sciences sociales: La longue durée. Annales 13, 725-753.

Braudel, F., 1976. The Mediterranean and the Mediterranean World in the Age of Philip II. Harper \& Row, New York.

Braudel, F., 1985a. The Structures of Everyday Life: The Limits of the Possible; Civilization and Capitalism, 15-18th Century.

Braudel, F., 1985b. The Wheels of Commerce: Civilization and Capitalism, 15-18th Century.

Braudel, F., 1985c. The Perspective of the World: Civilization and Capitalism, 15-18th Century.

Breschi, S., Malerba, F., 1997. Sectoral innovation systems: technological regimes, Schumpeterian dynamics, and spatial Boundaries. In: Edquist, C. (Ed.), Systems of Innovation: Technologies, Institutions and Organizations. Pinter, London, Washington.

Callon, M., 1991. Techno-economic networks and irreversibility. In: Law, J. (Ed.), A Sociology of Monsters: Essays on Power, Technology and Domination. Routledge, London.

Callon, M., Laredo, P., Rabeharisoa, V., 1992. The management and evaluation of technological programs and the dynamics of technoeconomic networks: the case of the AFME. Research Policy 21, 215-236.

Carlsson, B. (Ed.), 1997. Technological Systems and Industrial Dynamics. Kluwer Academic Publishers, Boston, Dordrecht, London.

Carlsson, B., Stankiewicz, R., 1991. On the nature, function and composition of technological systems. Journal of Evolutionary Economics 1, 93-118.

Carroll, G.R. (Ed.), 1988. Ecological Models of Organizations. Ballinger, Cambridge, MA.

Carroll, G.R., Harrison, J.R., 1994. On the historical efficiency of competition between organizational populations. American Journal of Sociology 100, 720-749.

Clark, K.B., 1985. The interaction of design hierarchies and market concepts in technological evolution. Research Policy 14, 235-251.

Constant, E.W., 1980. The Origins of the Turbojet Revolution. The John Hopkins University Press, Baltimore, London. 
Coombs, R., Green, K., Richards, A., Walsh, V. (Eds.), 2001. Technology and the Market: Demand, Users and Innovation. Edward Elgar, Cheltenham, UK.

Dawson, V.P., 1995. The American turbojet industry and British competition: the mediating role of government research. In: Leary, W.M. (Ed.), From Airships to Airbus: The History and Commercial Aviation. Infrastructure and Environment, vol. 1. Smithsonian Institution Press, Washington, London.

Dierikx, M., Bouwens, B., 1997. Building Castles of the Air: Schiphol Amsterdam and The Development of Airport Infrastructure in Europe, 1916-1996. Sdu Publishers, Den Haag.

Douglas, D.G., 1995. Airports and systems and systems of airports: airports and urban development before World War II. In: Leary, W.M. (Ed.), From Airships to Airbus: The History of Civil and Commercial Aviation. Infrastructure and Environment, vol. 1. Smithsonian Institution Press, Washington, London.

Du Gay, P., Hall, S., Janes, L., MacKay, H., Negus, K., 1997. Doing Cultural Studies: The Story of the Sony Walkman. Sage Publications, London.

Edgerton, D., 1991. England and the Aeroplane: An Essay on a Militant and Technological Nation. Macmillan, Basingstoke.

Eldridge, C., 2000. Electronic eyes for the Allies: Anglo-American cooperation on radar development during World War II. History and Technology 17, 1-20.

Emery, F., 1993. Characteristics of socio-technical systems. In: Trist, E., Murray, H. (Eds.), The Social Engagement of Social Science: A Tavistock Anthology, The Socio-technical Perspective, vol. 2. University of Pennsylvania Press, Philadelphia, PA.

Engel, J.A., 2000. We are not concerned who the buyer is: engine sales and Anglo-American security at the dawn of the jet age. History and Technology 17, 43-67.

Etzkowitz, H., Leydesdorff, L., 2000. The dynamics of innovation: from national systems and 'mode 2' to a triple helix of university-industrygovernment relations. Research Policy 29, 109-123.

Field, A., 1985. International Air Traffic Control: Management of the World's Airspace. Pergamon Press Ltd., Oxford.

Fishbein, S.B., 1995. Flight Management Systems: The Evolution of Avionics and Navigation Technology. Praeger, Westport.

Fleck, J., 1993. Configurations: crystallizing contingency. The International Journal of Human Factors in Manufacturing 3, 15-36.

Fleck, J., 2000. Artefact $\leftarrow \rightarrow$ activity: the coevolution of artefacts, knowledge and organization in technological innovation. In: Ziman, J. (Ed.), Technological Innovation as an Evolutionary Process. Cambridge University Press, Cambridge.

Freeman, C., Louçă, F., 2001. As Time Goes By: From the Industrial Revolutions to the Information Revolution. Oxford University Press, Oxford.

Freeman, C., Perez, C., 1988. Structural crisis of adjustment, business cycles and investment behaviour. In: Dosi, G., Freeman, C., Nelson, R., Silverberg, G., Soete, L. (Eds.), Technical Change and Economic Theory. Pinter, London.

Gardiner, J.P., 1984. Design trajectories for airplanes and automobiles. In: Freeman, C. (Ed.), Design, Innovation and Long Cycles in Economic Development. Frances Pinter Publishers, London.

Geels, F.W., 2002. Technological transitions as evolutionary reconfiguration processes: a multi-level perspective and a case-study. Research Policy 31, 1257-1274.

Geels, F.W., 2004. From sectoral systems of innovation to socio-technical systems: insights about dynamics and change from sociology and institutional theory. Research Policy 33, 897-920.

Geels, F.W., 2005. Technological Transitions and System Innovations: A Co-evolutionary and Socio-Technical Analysis. Edward Elgar, Cheltenham.

Gilbert, G.A., 1973. Air Traffic Control: The Uncrowded Sky. Smithsonian Institution Press, Washington.

Green, K., 1992. Creating demand for biotechnology: shaping technologies and markets. In: Coombs, R., Saviotti, P., Walsh, V. (Eds.),
Technological Change and Company Strategies: Economic and Sociological Perspectives. Academic Press, London.

Griffith, T.L., Dougherty, D.J., 2001. Beyond socio-technical systems: introduction to the special issue. Journal of Engineering and Technology Management 18 (3-4), 207-218.

Gunston, B., 1997. The Development of Jet and Turbine Aero Engines. Patrick Stephens Limited, Sparkford.

Hannan, M.T., Freeman, J.H., 1989. Organizational Ecology. Harvard University Press, Cambridge, MA.

Heppenheimer, T.A., 1995. Turbulent Skies: The History of Commercial Aviation. Wiley, New York.

Hobday, M., 1998. Product complexity, innovation and industrial organisation. Research Policy 26, 689-710.

Hobday, M., Rush, H., Tidd, J., 2000. Innovation in complex products and systems. Research Policy 29 (7-8), 793-804.

Hoogma, R., Kemp, R., Schot, J., Truffer, B., 2002. Experimenting for Sustainable Transport: The Approach of Strategic Niche Management. Spon Press, London, New York.

Hopps, R.H., 1978. Aircraft Manufacturing and Utilization. WTO, IATA, Madrid, Geneva.

Hughes, T.P., 1983. Networks of Power: Electrification in Western Society, 1880-1930. Johns Hopkins University Press, Baltimore.

Hughes, T.P., 1987. The evolution of large technological systems. In: Bijker, W.E., Hughes, T.P., Pinch, T. (Eds.), The Social Construction of Technological Systems: New Directions in the Sociology and History of Technology. The MIT Press, Cambridge, MA.

Kemp, R., Schot, J., Hoogma, R., 1998. Regime shifts to sustainability through processes of niche formation: the approach of strategic niche management. Technology Analysis and Strategic Management 10, 175-196.

Kemp, R., Rip, A., Schot, J., 2001. Constructing transition paths through the management of niches. In: Garud, R., Karnoe, P. (Eds.), Path Dependence and Creation. Lawrence Erlbaum Associates Publishers, Mahwah, NJ.

Kline, S.J., Rosenberg, N., 1986. An overview of innovation. In: Landau, R., Rosenberg, N. (Eds.), The Positive Sum Strategy: Harnessing Technology for Economic Growth. National Academy Press, Washington, DC.

La Porte, T.R., 1991. The United States air traffic system: increasing reliability in the midst of rapid growth. In: Mayntz, R., Hughes, T.P. (Eds.), The Development of Large Technical Systems. Campus Verlag, Frankfurt am Main.

Latour, B., 1987. Science in Action. Harvard University Press, Cambridge, MA.

Latour, B., 1991. Society is technology made durable. In: Law, J. (Ed.), A Sociology of Monsters, Essays on Power, Technology and Domination. Routledge, London.

Law, J., 1987. Technology and heterogeneous engineering: the case of Portugese expansion. In: Bijker, W.E., Hughes, T.P., Pinch, T. (Eds.), The Social Construction of Technological Systems: New Directions in the Sociology and History of Technology. The MIT Press, Cambridge, MA.

Law, J., Callon, M., 1992. The life and death of an aircraft: a network analysis of technical change. In: Bijker, W.E., Law, J. (Eds.), Shaping Technology/Building Society: Studies in Sociotechnical Change. MIT Press, Cambridge, MA.

Law, J., Hassard, J. (Eds.), 1999. Actor Network Theory and After. Blackwell Publishers, Oxford.

Layton, E., 1971. Mirror-image twins: the communities of science and technology in 19th century America. Technology and Culture 12 (4), $562-580$.

Layton, E., 1976. American ideologies of science and engineering. Technology and Culture 17 (4), 688-701.

Leonard-Barton, D., 1988. Implementation as mutual adaptation of technology and organisation. Research Policy 17, 251-267.

Levinthal, D.A., 1998. The slow pace of rapid technological change: gradualism and punctuation in technological change. Industrial and Corporate Change 7 (2), 217-247. 
Leydesdorff, L., 2000. The triple helix: an evolutionary model of innovations. Research Policy 29, 243-255.

Leydesdorff, L., Etzkowitz, H., 1998. The triple helix as a model for innovation studies. Science and Public Policy 25 (3), 195-203.

Lundvall, B.A., 1988. Innovation as an interactive process: from user-producer interaction to the national system of innovation. In: Dosi, G., Freeman, C., Nelson, R., Silverberg, G., Soete, L. (Eds.), Technical Change and Economic Theory. Pinter, London.

Lynn, G.S., Morone, J.G., Paulson, A.S., 1996. Marketing and discontinuous innovation: the probe and learn process. California Management Review 38 (3), 8-37.

Malerba, F., 2002. Sectoral systems of innovation. Research Policy 31 (2), 247-264.

Mayntz, R., Hughes, T.P. (Eds.), 1988. The Development of Large Technical Systems. Westview Press, Boulner and Campus Verlag, Frankfurt.

Miller, R., Sawers, D., 1968. The Technical Development of Modern Aviation. Routledge \& Kegan Paul, London.

Miller, R., Hobday, M., Leroux-Demers, T., Olleros, X., 1995. Innovation in complex system industries: the case of flight simulation. Industrial and Corporate Change 4 (2), 363-400.

Nahum, A., 1997. Two-stroke or turbine? The aeronautical research committee and British aero-engine development in World War II. Technology and Culture 38, 312-354.

Nelson, R.R., 1994a. The co-evolution of technology, industrial structure, and supporting institutions. Industrial and Corporate Change 3 (1), 47-63.

Nelson, R.R., 1994b. Economic growth via the coevolution of technology and institutions. In: Leydesdorff, L., Van den Besselaar, P. (Eds.), Evolutionary Economics and Chaos Theory: New Directions in Technology Studies. Pinter Publishers, London.

Nelson, R.R., Winter, S.G., 1982. An Evolutionary Theory of Economic Change. Bellknap Press, Cambridge (Mass.).

Oudshoorn, N., Pinch, T. (Eds.), 2003. How Users Matter: The CoConstruction of Users and Technology. MIT Press, Cambridge, MA.

Rae, J.B., 1968. Climb to Greatness: The American Aircraft Industry, 1920-1960. MIT Press, Cambridge, MA.

Rip, A., Kemp, R., 1998. Technological change. In: Rayner, S., Malone, E.L. (Eds.), Human Choice and Climate Change. Battelle Press, Columbus, $\mathrm{OH}$.

Rosenberg, N., 1982. Inside the Black Box: Technology and Economics. Cambridge University Press, Cambridge.

Rosenberg, N., 1986. The impact of technological innovation: a historical view. In: Landau, R., Rosenberg, N. (Eds.), The Positive Sum Strategy: Harnessing Technology For Economic Growth. National Academy Press, Washington, DC.

Rosenkopf, L., Tushman, M., 1994. The coevolution of technology and organization. In: Baum, J., Singh, J. (Eds.), Evolutionary Dynamics of Organizations. Oxford University Press, Oxford.

Rotmans, J., Kemp, R., Van Asselt, M., 2001. More evolution than revolution: transition management in public policy. Foresight 3 (1), $15-31$.

Saviotti, P.P., 1996. Technological Evolution, Variety and the Economy. Edward Elgar, Cheltenham, UK.
Schot, J.W., 1998. The usefulness of evolutionary models for explaining innovation: the case of the Netherlands in the nineteenth century. History of Technology 14, 173-200.

Schot, J., Hoogma, R., Elzen, B., 1994. Strategies for shifting technological systems: the case of the automobile system. Futures 26, 1060-1076.

Smith, M.J.T., 1989. Aircraft Noise. Cambridge University Press, Cambridge.

Stankiewicz, R., 1992. Technology as an autonomous socio-cognitive system. In: Grupp, H. (Ed.), Dynamics of Science-Based Innovation. Springer, Berlin.

Summerton, J. (Ed.), 1994. Changing Large Technical Systems. Boulder, Westview Press, San Francisco, Oxford.

Tillinghast Jr., C.C., 1966. The air transport operator and the economic trend, 'Conjuncture' of Air Transport: The Interaction Between Air Transport and General Technical, Economic and Social Trends. ITA, Paris.

Tisdell, C., Seidl, I., 2004. Niches and economic competition: implications for economic efficiency, growth and diversity. Structural Change and Economic Dynamics 15, 119-135.

Todd, D., Simpson, J., 1986. The World Aircraft Industry. Croom Helm, London.

Trist, E., Murray, H. (Eds.), 1990. The Social Engagement of Social Science: A Tavistock Anthology, The Social Psychological Perspective, vol. 1. University of Pennsylvania Press, Philadelphia, PA.

Trist, E., Murray, H. (Eds.), 1993. The Social Engagement of Social Science: A Tavistock Anthology, The Socio-technical Perspective, vol. 2. University of Pennsylvania Press, Philadelphia, PA.

Tushman, M., Anderson, P., 1986. Technological discontinuities and organization environments. Administrative Science Quarterly 31, 439-465.

Tylecote, A., 1993. The Long Wave in the World Economy: The Current Crisis in Historical Perspective. Routledge, London, New York.

Unruh, G.C., 2000. Understanding carbon lock-in. Energy Policy 28, $817-830$.

Van de Ven, A.H., Garud, R., 1994. The coevolution of technical and institutional events in the development of an innovation. In: Baum, J.A., Singh, J.V. (Eds.), Evolutionary Dynamics of Organizations. Oxford University Press, New York, Oxford.

Van Dijck, J., 1998. Imagenation: Popular Images of Genetics. New York University Press, New York.

Zeitlin, J., 1995. Flexibility and mass production at war: aircraft manufacture in Britain, the United States, and Germany, 1939-1945. Technology and Culture 36, 46-79.

Dr. Frank Geels is Assistant Professor at the Department of Technology Management, Eindhoven University of Technology, the Netherlands. Using insights from sociology of technology, innovation studies, history of technology and evolutionary economics, his main research topic is the dynamics of technological transitions and system innovations. His conceptual work is grounded with case studies of historical transitions. 